\title{
Modulatory Effects of 6-Carboxymethylthiopurine on Activated Murine Macrophages
}

\author{
Marcio L. De Paula ${ }^{1}$, Fernanda G. Braga ${ }^{1}$, \\ Elaine S. Coimbra', Arturene M. L. Carmo², \\ Henrique C. Teixeira ${ }^{1}$, Adilson D. Da \\ Silva ${ }^{2}$, Maria A. Souza ${ }^{1}$ and Ana Paula \\ Ferreira $^{1, *}$ \\ ${ }^{1}$ Departamento de Parasitologia, Microbiologia e Imunologia, \\ Instituto de Ciências Biológicas, Universidade Federal de Juiz de \\ Fora, Juiz de Fora, MG, Brazil \\ ${ }^{2}$ Departamento de Quimica, Instituto de Ciências Exatas, \\ Universidade Federal de Juiz de Fora, Juiz de Fora, MG, Brazil \\ *Corresponding author: Ana Paula Ferreira, ana.paula@ufjf.edu.br
}

The immunological activity of macrophages against pathogens in hosts includes the phagocytosis and the production of nitric oxide. We report herein the investigation of the effect of 6-carboxymethylthiopurine on nitric oxide production by murine macrophages as well as its effect on the cell viability and proliferation after stimulus with Mycobacterium bovis bacille Calmette-Guérin, interferon-gamma or a combination of both. J774A.1 macrophages stimulated or not by bacille Calmette-Guérin $(20 \mu \mathrm{g} / \mathrm{mL})$, interferon-gamma or both, were cultured in the presence of 6-carboxymethylthiopurine (125, 250 and $500 \mu \mathrm{M})$. Nitric oxide production was measured by the Griess method and cell viability/proliferation by the diphenyltetrazolium assay [3-(4, 5-dimethylthiazol2-yl)-2, 5-diphenyltetrazolium bromide]. We observed an increase of J774A.1 cell proliferation after stimulus with bacille Calmette-Guérin at 125,250 and $500 \mu \mathrm{M}(69.1,124.0$ and $89.7 \%$, respectively) and with interferon-gamma at 125 and $250 \mu \mathrm{M} \quad(64.8 \%$ and $61.7 \%$, respectively) (p < 0.05). In all cultures treated with 6-carboxymethylthiopurine, interferon-gamma-activated nitric oxide production by J774A.1 cells decreased as well as when subjected to interferon-gamma plus bacille Calmette-Guérin stimuli at $500 \mu \mathrm{m}$ $(p<0.05)$. Altogether these data point to an antiinflammatory effect of 6-carboxymethylthiopurine on stimulated macrophages.

Key words: 6-carboxymethylthiopurine, immunological activity, inflammatory response, macrophage, nitric oxide

Received 25 January 2008, revised 21 March 2008 and accepted for publication 1 April 2008
6-Mercaptopurine (6-MP) (Figure 1) is an orally administered, waterinsoluble purine analog that is effective against acute lymphatic leukemia (1). Oral absorption of 6-MP, however, is quite erratic, with only $16-50 \%$ of the administered dose reaching the blood (2). With the goal of obtaining 6-MP derivatives more soluble for parenteral administration, various compounds were synthesized $(3,4)$.

6-Mercaptopurine is a 6-thiopurine analog of naturally occurring purine bases: hypoxantine and guanine. It is a phase-specific drug, inhibiting cell division in the S-phase of the cell cycle and it is a prodrug requiring intracellular activation by thiopurine nucleotides to exert an antileukemic effect (5). 6-Mercaptopurine inhibits phosphoribosylpyrophosphate amidotransferase by methylthioinosine nucleotides thus inhibiting de novo purine synthesis. Therefore, there is a purine deprivation, leading to an inhibition of DNA synthesis, decreased cell proliferation and antileukemic effect (6).

6-Mercaptopurine is an antimetabolite, which has been widely applied to treat childhood acute lymphoblastic leukemia, as well as being a major component of remission maintenance treatment $(7,8)$. Although 6-MP and its prodrug azathioprine (AZA) have been used in clinical practice as immunosuppressive drugs for more than 20 years, their mechanism of action is little known. This is largely because of the fact that they are by themselves inactive and must be transformed intracellularly into active 6-thioguanine (6-TG) metabolites (9). 6-Thioguanine may be used to treat AZA and 6-MPintolerant inflammatory bowel disease patients because 6-TG is considered to be an escape maintenance immunosuppressant (10). 6-Mercaptopurine and AZA act on T and B-lymphocytes in vitro, inhibit the expression of surface receptors and block mitogen-stimulated immunologic response. Low doses of 6-MP are applied to the treatment of ulcerative colitis, Crohn's disease and multiple sclerosis (11-13).

Different 6-alkylthiopurine and analogs were prepared and tested for the carcinostatic and leishmanial activity and have more proven inhibitory effects than the previously known 6-MP and have no toxic<smiles>Sc1ncnc2nc[nH]c12</smiles>

Figure 1: Structure of 6-mercaptopurine. 


\section{De Paula et al.}

side-effects (2,3,14). 6-Carboxymethylthiopurine (6-CMMP; Figure 2) (15), a soluble compound in water, has also significant antileishmanial activity reported elsewhere (4). Unlike humans, leishmania parasites cannot make purines de novo and must therefore obtain purine bases and nucleotides from the host cell and then metabolize these to nucleotides by salvage pathway (16). A similar mechanism occurs in malaria parasites, which have also demonstrated significant sensitivity to 6-MP, 6-TG and other compounds (17).

Macrophages are central components of the innate immunity and also play a major role in initiating the adaptive immunity. In both cases, its immune function can be activated by contact with other cells, with different cytokines such as interferon-gamma (IFN- $\gamma$ ) and with a variety of components of foreign organisms. The immunologic activity of the macrophages against pathogens in hosts includes phagocytosis and the production of nitric oxide (NO) (18). Studies in vitro with a variety of macrophage cell lines have shown J774A.1 cell line to be an important tool for analyzing the influence of drugs on macrophage-like function of these cells (19-21).

Our goal was to investigate the effect of 6-CMMP on NO production by J774A.1 cells as well as its effect on the cell viability and proliferation after stimulus with Mycobacterium bovis bacille Calmette-Guérin (BCG), IFN- $\gamma$ or a combination of both.

\section{Results}

\section{Effect of 6-CMMP on NO synthesis by activated J774A. 1 cells}

The 6-CMMP was assessed for its activity on NO production in BCG and/or IFN- $\gamma$-activated J774A.1 macrophages at concentrations 125, 250 and $500 \mu \mathrm{M}$. In all cultures treated with 6-CMMP, the IFN$\gamma$-activated NO production by J774A.1 cells decreased (30.1, 49.2 and $51.1 \%$ at 125,250 and $500 \mu \mathrm{M}$, respectively) in comparison with control $(\mathrm{p}<0.05)$ (Figure 3). In reference to the $500 \mu \mathrm{M}$ treatment with 6-CMMP of J774A.1 cells activated by both IFN- $\gamma$ and BCG, there was a reduction of $35.2 \%(p<0.05)$ (Figure 3). Furthermore, when J774A.1 cells activated by both IFN- $\gamma$ and BCG were subjected to 125 and $250 \mu \mathrm{M}$ treatment or by BCG only, 6-CMMP<smiles>O=C(O)CSc1ncnc2[nH]cnc12</smiles>

Figure 2: Structure of 6-carboxymethylthiopurine. 6-CMMP was synthesized from 6-MP. $\mathrm{H}_{2} \mathrm{O}$ as described in the experimental section.

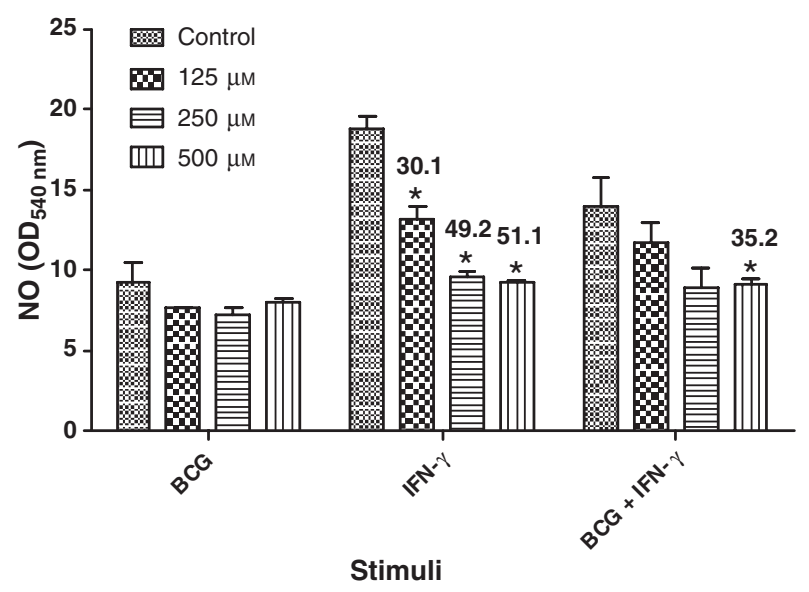

Figure 3: NO production by J774A.1 macrophages treated or not with 6-CMMP. Cells were stimulated with $20 \mu \mathrm{g} / \mathrm{mL}$ BCG or $0.6 \mathrm{ng} / \mathrm{mL}$ IFN- $\gamma$ or a combination of both, and incubated with increasing amounts of 6-CMMP $(125-500 \mu \mathrm{M})$ for $48 \mathrm{~h}$. After incubation, the supernatants were collected and assayed for nitrite determination using the Griess reagent. Each bar represents the mean \pm standard deviation of sextuplicate cultures. Numerical data on the top of the bars represent the percentage of NO production inhibition in comparison with the non-6-CMMP-treated control. ${ }^{*} p<0.05$.

also decreased NO production, although with no statistical significance (Figure 3).

\section{Effect of 6-CMMP on cell proliferation and viability}

The proliferation and viability were analyzed on J774A.1 cell cultures stimulated with BCG or IFN- $\gamma$ or a combination of both and evaluated through the cellular respiration levels determined by a colorimetric MTT assay. In BCG-activated J774A.1 cells, this drug induced proliferation at all concentrations (69.1, 124.0 and $89.7 \%$ at 125,250 and $500 \mu \mathrm{M}$, respectively) in comparison with control $(p<0.05)$ (Figure 4). Similarly, this effect was observed when the IFN- $\gamma$-activated murine macrophages were treated with 6-CMMP at $125 \mu \mathrm{M}(64.8 \%)$ and $250 \mu \mathrm{M}(61.7 \%)(p<0.05)$ (Figure 4). When both stimuli were applied, there was a slight cell proliferation at all concentrations tested, although with no statistical significance (Figure 4).

\section{Discussion}

In this study, the potential role of 6-CMMP as an anti-inflammatory drug was examined. Increasing amounts of 6-CMMP were tested based on previous findings in which 6-MP, its parent compound, was analyzed and demonstrated no effect on NO production (22). Cytokines such as IFN- $\gamma$ and microbial products lead macrophages to release $\mathrm{NO}$ and other mediators. In some acute and cronic inflammatory diseases, the high-output path of uncontrolled NO production can cause cell and tissue damage as well as contributing to septic shock and thereby kill the host (23). The down-regulation 
Effect of 6-CMMP on NO production

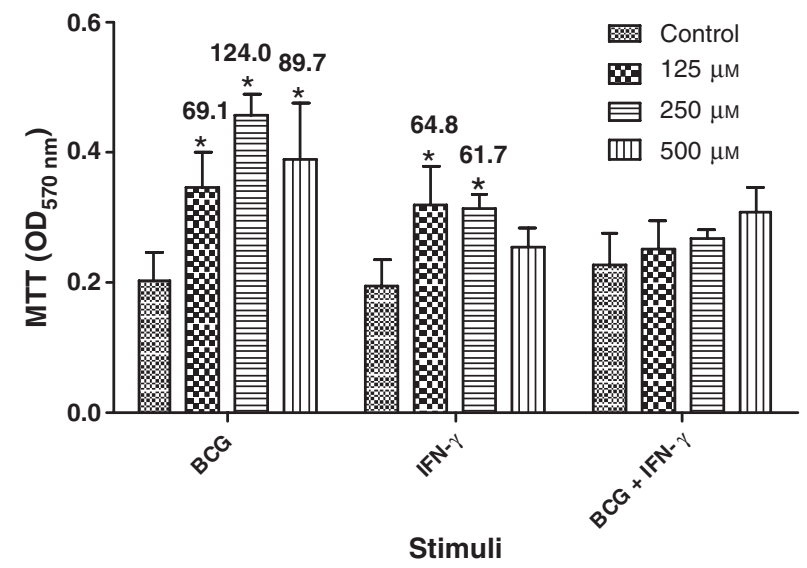

Figure 4: Cell viability and proliferation of J774A.1 macrophages treated with 6-CMMP. Cells were stimulated with BCG $(20 \mu \mathrm{g} / \mathrm{mL})$ and/or IFN- $\gamma(0.6 \mathrm{ng} / \mathrm{mL})$ and incubated with $125-500 \mu \mathrm{M}$ 6-CMMP for $48 \mathrm{~h}$. Each bar represents the mean \pm standard deviation of sextuplicate cultures. Numerical data on the top of the bars represent the percentage of proliferation in comparison with the control. ${ }^{*} p<0.05$.

of NO is important in response to the formation of radicals such as superoxide, owing to the fact that they promote indirect oxidative damage in biological systems and cytotoxic action against cells in culture (24). Thus, the use of exogenous modulators becomes necessary.

Several drugs and plant extracts have been reported to modify NO production by murine macrophages (25-28). Herein, 6-CMMP exhibited this property at all concentrations and it performed significantly in a dose-dependent manner when macrophages were activated by IFN- $\gamma$, showing pronounced effects at $500 \mu \mathrm{M}$. In general, when macrophages are overstimulated by cytokines such as IFN- $\gamma$, there is an excessive production of NO which leads to cytotoxic effects and reduced cell viability (29). In this context, 6-CMMP controlled proliferative effects and sustain macrophage viability, suggesting that at least in part, it interferes with NO synthesis pathway in which IFN- $\gamma$ acts like a stimulus. Similarly, diminished NO production was observed when BCG plus IFN- $\gamma$ stimuli were applied, especially at the highest concentration. Such combination of stimuli were used to simulate an immune response in vivo where the IFN- $\gamma$ produced by $\mathrm{T}$ lymphocytes acts on macrophages, producing NO and other mediators so that they may engulf and ingest microorganisms or foreign bodies, including M. bovis (30). The BCG stimulus only was not sufficient to lead to NO production in contrast to marked macrophage proliferation noted at all concentrations used. It suggests not only that the presence of IFN- $\gamma$ is highly required so that 6-CMMP reduces NO production but also that the pathway by which this compound acts on NO levels is different from cellular proliferation pathway when BCG stimulus is applied. The characteristics demonstrated by 6-CMMP are appropriate for decreasing NO overproduction in inflammation processes, which may avoid the tissue damage and the carcinogenic action of free radicals $(24,31)$. It may be pointed out therefore that 6-CMMP might act as an antiinflammatory agent.
Many of the responses of the immune system initiate the destruction and clearance of invading organisms and any toxic molecules produced by them and, as a result, a large consumption of neutrophils, macrophages and lymphocytes takes place (32). In this way, the increase of cell survival, abrogation of programmed cell death or induction of proliferation might become essential. Several cytokines generated throughout the innate and adaptive immune reactions such as granulocyte/macrophage colony-stimulating factor and macrophage colony-stimulating factor stimulate the proliferation, growth and differentiation of progenitor cells from bone marrow $(33,34)$. The immune and inflammatory conditions therefore lead to the production of new leukocytes, which will replace those which were damaged in these processes.

In this study, the 6-CMMP was found to stimulate cell proliferation after different stimuli, suggesting no cytotoxicity effects. As observed on NO production, potential anti-inflammatory effects of the 6-CMMP were also pronounced when IFN- $\gamma$ stimulus was applied. This cytokine is involved in the regulation of immune and inflammatory responses and its inappropriate production can lead to autoimmune disorders (35). Interestingly, 6-CMMP was shown to have no effect on J774A.1 cells submitted to IFN- $\gamma$ plus BCG stimuli. In this context, although proliferative events were not observed, this compound was capable of maintaining viability of IFN- $\gamma$ plus BCG-activated macrophages at all concentrations used. Accumulating evidence has indicated that the expression of enzymes such as heme oxygenase-1 in macrophages is an element of the repair processes that occur during the resolution of inflammation leading to healing and tissue repair (36). In this context, the ability of 6-CMMP to sustain cell viability and to stimulate proliferation might become of great relevance.

\section{Conclusions and Future Directions}

Taken together, these data suggest that 6-CMMP might function as a potential anti-inflammatory agent not only by downmodulating NO production but also by maintaining cell viability of macrophages. Additionally, owing to the sustained NO generation by macrophages endowing them with cytostatic and cytotoxic characteristics, this compound becomes especially important in the resolution of immune reactions and its homeostasis. Moreover, other analogs of the 6-alkylthiopurines should be synthesized so that a full structure-activity relationship (SAR) study can be done. Further studies in vitro and in vivo are required to assess the pharmacokinetic properties as well as others immunologic and biochemical activities of 6-CMMP, including its action on phosphoribosylpyrophosphate amidotransferase in order to better understand its therapeutic value.

\section{Experimental Section}

\section{Material and methods}

\section{6-CMMP preparation}

The 6-CMMP can be prepared by two methods. Method A: 6- $\mathrm{MP} \mathrm{H}_{2} \mathrm{O}(5 \mathrm{~g}, 29.3 \mathrm{mmol})$ in $60 \mathrm{~cm}^{3} 1 \mathrm{~N} \mathrm{NaOH}$ was treated with $\mathrm{CICH}_{2} \mathrm{CO}_{2} \mathrm{H}(3 \mathrm{~g}, 31.9 \mathrm{mmol})$ and heated to boiling for $15 \mathrm{~min}$, after 


\section{De Paula et al.}

which the reaction mixture was acidified with $13 \mathrm{~cm}^{3} 2 \mathrm{~N} \mathrm{HCl}$ over $1 \mathrm{~h}$, chilled, filtered and the residue $(4.55 \mathrm{~g})$ was recrystalized from $1 \mathrm{~L}$ boiling $\mathrm{H}_{2} \mathrm{O}$ to gave $3.7 \mathrm{~g}$ (60\% yield) of 6-CMMP (37). Method B: as previously described (3).

\section{Macrophage culture and in vitro treatment}

Macrophages from the J774A.1 cell line were cultured in sextuplicate in $25 \mathrm{~cm}^{3}$ flasks in RPMI-1640 medium, supplemented with $5 \%$ heat-inactivated fetal bovine serum (FBS), 2 mM L-glutamine, $100 \mathrm{U} / \mathrm{mL}$ penicillin and $100 \mu \mathrm{g} / \mathrm{mL}$ streptomycin (RPMI 5\%), in a humidified incubator, at $37{ }^{\circ} \mathrm{C}$ and $5 \% \mathrm{CO}_{2}$ atmosphere. Cells were added $\left(1 \times 10^{6}\right.$ cells $\left./ \mathrm{mL}\right)$ to 96 -well microtiter plates $(100 \mu \mathrm{L} /$ well $)$ and they were stimulated with BCG $(20 \mu \mathrm{g} / \mathrm{mL}$; Fundação Athaulpho de Paiva, RJ, Brazil) and/or IFN- $\gamma(0.6 \mathrm{ng} / \mathrm{mL})$. Increasing amounts of 6-CMMP $(0-500 \mu \mathrm{M})$ were added simultaneously to the culture medium. After $48 \mathrm{~h}$ incubation, the cells were used to assess the proliferation and cellular viability, and their supernatants were harvested for $\mathrm{NO}_{3}{ }^{-}$and $\mathrm{NO}_{2}{ }^{-}$determination.

\section{Determination of NO production}

The production of $\mathrm{NO}$ was estimated from the accumulation of $\mathrm{NO}_{3}{ }^{-}$and $\mathrm{NO}_{2}{ }^{-}$in $\mathrm{J} 774 \mathrm{~A} .1$ supernatants using the Griess reagent, as previously described (18,31). Briefly, equal volumes (100 $\mu \mathrm{L})$ of nitrite samples for standard curve and Griess reagent (1\% sulphanilamide plus $0.1 \% \alpha$-naphtylamine $(\mathrm{V} / \mathrm{v})$ in $2.5 \%$ phosphoric acid) (Sigma Chemical Laboratories, St Louis, MO, USA) were mixed and incubated at room temperature for $10 \mathrm{~min}$. The absorbance values were measured at $540 \mathrm{~nm}$ using a microplate reader and the results were expressed as an optic density. When statistically significant, the results were also expressed in percentage of the NO production inhibition in comparison with controls.

\section{MTT assay for cellular viability and proliferation}

Cell viability and proliferation of 6-CMMP-treated J774A.1 cells stimulated with IFN- $\gamma$ and/or BCG were evaluated by the $3-(4,5-$ dimethylthiazol-2-yl)-2, 5-diphenyltetrazolium bromide (MTT) assay (38). Briefly, cells were incubated in 96-well plates for $4 \mathrm{~h}$ with $10 \mu \mathrm{L}$ of $5 \mathrm{mg} / \mathrm{mL}$ MTT (Sigma) in $90 \mu \mathrm{L}$ of $5 \%$ RPMI, after collecting supernatants for NO measurement. The insoluble purple particles were solubilized in $0.1 \mathrm{~N} \mathrm{HCl}$ in isopropanol and the absorbance was measured at $570 \mathrm{~nm}\left(\mathrm{OD}_{570}\right)$. The $\mathrm{OD}_{570}$ values obtained from supernatants of the cells cultured with BCG or IFN- $\gamma$ or both, and 6-CMMP were considered to be experimental conditions, whereas the $\mathrm{OD}_{570}$ values obtained for samples cultured with $5 \%$ RPMI only were considered as controls. When statistically significant, the cell viability results were also expressed in percentage of proliferation in comparison with controls.

\section{Statistical analysis}

Statistical analysis was done using two-way ANOVA and Bonferroni correction as a post-test. The obtained results were reported as the mean \pm standard deviation and the levels of $p<0.05$ were chosen as the statistical significance criteria.

\section{Acknowledgments}

This work was supported by FAPEMIG, CAPES and CNPq. We are grateful to the Empresa Microbiológica Química e Farmacêutica Ltda for the provision of 6-mercaptopurine.

\section{References}

1. Burchenal J.H., Murphy M.L., Ellison R.R., Sykes M.P., Tan T.C., Leone L.A., Karnof-sky D.A., Craver L.F., Dargeon H.W., Rhoads C.P. (1953) Clinical evaluation of a new antimetabolite, 6-mercaptopurine, in the treatment of leukemia and allied diseases. Blood;8:965-999.

2. Choe Y.H., Greenwald R.B., Conover C.D., Zhao H., Longley C.B., Guan S. (2004) PEG prodrugs of 6-mercaptopurine for parenteral administration using benzyl elimination of thiols. Oncol Res; 14:455-468.

3. Braga F.G., Coimbra E.S., de Oliveira Matos M., Lino Carmo A.M., Cancio M.D., Da Silva A.D. (2007) Synthesis and biological evaluation of some 6-substituted purines. Eur J Med Chem;42:530-537.

4. Da Silva A.D., Machado A.S., Tempete C., Gero M.R. (1994) Synthesis and biological activity of methyl-D-glucopyranoside derivatives of mercaptopurine and mercaptopyrimidine. Eur $\mathrm{J}$ Med Chem;29:149-152.

5. Rang H.P., Dale M.M., Ritter J.M. (1999) Cancer chemotherapy. In: Rang H.P., Dale M.M., Ritter J.M., editors. Pharmacology. Edinburgh, UK: Harcourt Brace Co Ltd; p. 663-684.

6. Dervieux T., Brenner T.L., Hon Y.Y., Zhou Y., Hancock M.L., Sandlund J.T., Rivera G.K., Ribeiro R.C., Boyett J.M., Pui C., Relling M.V., Evans W.E. (2002) De novo purine synthesis inhibition and antileukemic effects of mercaptopurine alone or in combination with methotrexate in vivo. Blood;100:12401247.

7. Welch J.C., Lilleyman J.S. (1996) 6-Mercaptopurine dose escalation and its effect on drug tolerance in childhood lymphoblastic leukaemia. Cancer Chemother Pharmacol;38:113-116.

8. Pui C.H., Evans W.E. (1998) Acute Iymphoblastic leukemia. N Engl J Med;339:605-615.

9. Cuffari C., Li D.Y., Mahoney J., Barnes Y., Bayless T.M. (2004) Peripheral blood mononuclear cell DNA 6-thioguanine metabolite levels correlate with decreased interferon-gamma production in patients with Crohn's disease on AZA therapy. Dig Dis Sci;49:133-137.

10. de Boer N.K., Derijks L.J., Gilissen L.P., Hommes D.W., Engels L.G., de-Boer S.Y., den Hartog G., Hooymans P.M., Makelburg A.B., Westerveld B.D., Naber A.H., de Jong D.J., Mulder C.J. (2005) On tolerability and safety of a maintenance treatment with 6-thioguanine in azathioprine or 6-mercaptopurine intolerant IBD patients. World J Gastroenterol;11:5540-5544.

11. Hibi T., Iwao Y., Yajima T., Inoue N., Ueno Y., Takaishi $H_{.}$, Watanabe M., Ishii H. (1995) Immunosuppressive agents in the treatment of Crohn's disease and ulcerative colitis. J Gastroenterol;30(Suppl. 8):121-123.

12. Palace J., Rothwell P. (1997) New treatments and azathioprine in multiple sclerosis. Lancet;350:261. 


\section{Effect of 6-CMMP on NO production}

13. Hommes D.W., Oldenburg B., van Bodegraven A.A., van Hogezand R.A., de Jong D.J., Romberg-Camps M.J., van der Woude J., Dijkstra G., Dutch Initiative on Crohn and Colitis (ICC). (2006) Guidelines for treatment with infliximab for Crohn's disease. Neth J Med;64:219-229.

14. Escobar P., Matu S., Marques C., Croft S.L. (2002) Sensitivities of Leishmania species to hexadecylphosphocholine (miltefosine) ET-18-OCH(3) (edelfosine) and amphotericin B. Acta Trop;81:151157.

15. Gordon P.B., Seglen P.O. (1982) 6-Substituted purines: a novel class of inhibitors of endogenous protein degradation in isolated rat hepatocytes. Arch Biochem Biophys;217:282-294.

16. Boitz J.M., Ullman B. (2006) Leishmania donovani singly deficient in HGPRT, APRT or XPRT are viable in vitro and within mammalian macrophages. Mol Biochem Parasitol;148:24-30.

17. Queen S.A., Jagt D.L., Reyes P. (1990) In vitro susceptibilities of Plasmodium falciparum to compounds which inhibit nucleotide metabolism. Antimicrob Agents Chemother;34:1393-1398.

18. Reis D., Souza M., Mineo J., Espindola F. (2001) Myosin V and iNOS expression is enhanced in $\mathbf{J} 774$ murine macrophages treated with IFN-gamma. Braz J Med Biol Res;34:221-226.

19. Higa F., Kusano N., Tateyama M., Shinzato T., Arakaki N., Kawakami K., Saito A. (1998) Simplified quantitative assay system for measuring activities of drugs against intracellular Legionella pneumophila. J Clin Microbiol;36:1392-1398.

20. Simmons D.L., Botting R.M., Robertson P.M., Madsen M.L., Vane J.R. (1999) Induction of an acetaminophen-sensitive cyclooxygenase with reduced sensitivity to nonsteroid antiinflammatory drugs. Proc Natl Acad Sci USA;96:3275-3280.

21. Safir N., Wendel A., Saile R., Chabraoui L. (2003) The effect of selenium on immune functions of $\mathbf{J} 774.1$ cells. Clin Chem Lab Med;41:1005-1011.

22. Moeslinger T., Friedl R., Spieckermann P.G. (2006) Inhibition of inducible nitric oxide synthesis by azathioprine in a macrophage cell line. Life Sci;79:374-381.

23. MacMicking J., Xie O.W., Nathan C. (1997) Nitric oxide and macrophage function. Annu Rev Immunol;15:323-350.

24. Maeda H., Akaike T. (1998) Nitric oxide and oxygen radicals in infection, inflammation, and cancer. Biochemistry (Mosc);63:854865.

25. Ferreira A.P., Soares G.L.G., Salgado C.A., Gonçalves L.S., Teixeira F.M., Teixeira H.C. (2003) Immunomodulatory activity of Mollugo verticillata L. Phytomedicine;10:154-158.

26. Napolitano D.R., Mineo J.R., de Souza M.A., de Paula J.E., Espindola L.S., Espindola F.S. (2005) Down-modulation of nitric oxide production in murine macrophages treated with crude plant extracts from the Brazilian Cerrado. J Ethnopharmacol;99:37-41.

27. Park J.H., Oh S.M., Lim S.S., Lee Y.S., Shin H.K., Oh Y.S., Choe N.H., Park J.H., Kim J.K. (2006) Induction of heme oxygenase-1 mediates the anti-inflammatory effects of the ethanol extract of Rubus coreanus in murine macrophages. Biochem Biophys Res Commun;351:146-152.

28. Choi S.Y., Ko H.C., Ko S.Y., Hwang J.H., Park J.G., Kang S.H., Han S.H., Yun S.H., Kim S.J. (2007) Correlation between flavonoid content and the NO production inhibitory activity of peel extracts from various citrus fruits. Bio Pharm Bull;30:772-778.

29. Niedbala W., Cai B., Liew F.Y. (2006) Role of nitric oxide in the regulation of $T$ cell functions. Ann Rheum Dis;65(Suppl. 3): iii37-40.

30. Cunha F.Q., Assreuy J., Moncada S., Liew F.Y. (1993) Phagocytosis and induction of nitric oxide synthase in murine macrophages. Immunology;79:408-411.

31. Chi D.S., Qui M., Krishnaswamy G., Li C., Stone W. (2003) Regulation of nitric oxide production from macrophages by lipopolysaccharide and catecholamines. Nitric 0xide;8:127-132.

32. Alberts B., Bray D., Lewis J., Raff M., Roberts K., Watson J.D. (1994) Differentiated cells and the maintenance of tissues. In: Alberts B., Bray D., Lewis J., Raff M., Roberts K., Watson J.D., editors. Molecular Biology of the Cell. New York, USA: Garland Publishing Inc; p. 1161-1175.

33. Xu J., Lucas R., Schuchmann M., Kuhnle S., Meergans T., Barreiros A.P., Lohse A.W., Otto G., Wendel A. (2003) GM-CSF restores innate, but not adaptive, immune responses in glucocorticoidimmunosuppressed human blood in vitro. J Immunol;171: 938-947.

34. Kobayashi S.D., Voyich J.M., Whitney A.R., DeLeo F.R. (2005) Spontaneous neutrophil apoptosis and regulation of cell survival by granulocyte macrophage-colony stimulating factor. J Leukoc Biol;78:1408-1418.

35. Awara W.M., El-Sisi A.E., El-Refaei M., El-Naa M.M., El-Desoky K. (2005) Insulinotropic and anti-inflammatory effects of rosiglitazone in experimental autoimmune diabetes. Rev Diabet Stud;2:146-156.

36. Morse D., Choi A.M. (2002) Heme oxygenase-1: the "emerging molecule" has arrived. Am J Respir Cell Mol Biol;27:8-16.

37. Ellion G.B., Goodman I., Lange W., Hitchings G.H. (1959) Purines related to 6-mercaptopurine and thioguanine. JACS;81:18981902.

38. Mosmann T. (1983) Rapid colorimetric assay for cellular growth and survival: application to proliferation and cytotoxicity assays. J Immunol Methods;65:55-63. 